Original Article

Artigo Original

Humberto de Oliveira Simões ${ }^{1}$ Ana Cláudia Figueiredo Frizzo ${ }^{2}$

Sthella Zanchetta ${ }^{1}$

Miguel Ângelo Hyppolito ${ }^{1}$

Ana Cláudia Mirândola Barbosa

Reis $^{1}$

Keywords

P300 Evoked Potentials

Young Adult

Hearing

Electrophysiology

Audiology

\title{
Variables in P300 recording: task type and electrode position
}

\begin{abstract}
Purpose: To analyze the latency and amplitude of $\mathrm{P} 300$ responses obtained with electrodes positioned at $\mathrm{Cz}$ and $\mathrm{Fz}$ and in different tasks of infrequent stimulus identification in normal hearing individuals. Methods: Forty adults of both genders participated in the study. Three recordings with three different tasks were obtained for the identification of the infrequent stimulus; simultaneous recordings were obtained from $\mathrm{Cz}$ and $\mathrm{Fz}$ positions. Results: $\mathrm{Cz}$ position showed significantly greater amplitudes and lower latencies than Fz. Regarding the three tasks, only "pronouncing the word 'thin" was different from "raising a finger", with lowest latencies for the verbal task. Regarding amplitude, significantly higher values were observed for "raising a finger", followed by "pronouncing the word "thin"” and mental counting. Conclusion: Cz obtained the best values, highest amplitude and lowest latency. Lowest latencies were obtained for the task of "pronouncing the word "thin" "and the highest amplitudes were obtained for "raising a finger".
\end{abstract}

Study carried out at the Speech-Language Pathology and Audiology Course, School of Medicine of Ribeirão Preto, Universidade de São Paulo - USP - Ribeirão Preto (SP), Brazil.

${ }^{1}$ Universidade de São Paulo - USP - Ribeirão Preto (SP), Brazil.

${ }^{2}$ Universidade Estadual Paulista - UNESP - Marília (SP), Brazil.

Financial support: This work was supported by the Institutional Program for Scientific Initiation Scholarship - Santander.

Conflict of interests: nothing to declare.

de São Paulo - USP

Av. Bandeirantes, 3600, Campus

Universitário, Ribeirão Preto (SP),

Brazil, CEP: 14049-900.

E-mail: anaclaudia@fmrp.usp.br

Received: July 17, 2015

Accepted: February 19, 2016 


\section{INTRODUCTION}

There has been a significant increase in publications focused on studying the Hearing System, mainly regarding the Central Auditory Nervous System (CANS), by behavioral, electrophysiological and imaging systems ${ }^{(1)}$.

One form of CANS assessment is through evoked potentials obtained by recording and measuring responses to sensory stimuli captured on the skull surface. Long-latency evoked potentials, especially cognitive potentials (CP), are directly influenced by the patient motivation, his/her level of attention, the type of task requested and stimulus of previous experience. $\mathrm{P} 300 \mathrm{CP}$ is also denoted endogenous or event-related potential ${ }^{(2,3)}$.

Hearing assessment using long-latency potentials in combination with behavioral tests to the central hearing system has proved to be a promising and potent method to the best understanding of this system ${ }^{(4)}$.

Among different audiological procedures that assess the central auditory system, integrity is the information obtained through auditory evoked potentials. These, in turn, play a significant role in audiology, since they provide data on nervous system in response to acoustic stimulation, are non-invasive and provide information to monitor the natural speech and hearing development when necessary ${ }^{(5)}$.

The Long-Latency Auditory Evoked Potential (LLAEP), P300, has been studied to assess hearing function in different situations. It can also be a clinical accessory to the neurophysiological measurement of the cognitive process.

The motivation to establish a protocol for behavioral assessment and individuals follow-up with variation in the hearing system in combination with objective assessments has increasingly been emphasized in the literature, not only for individuals with hearing loss or attention disorders, but also for individuals with degenerative diseases, allowing a data comparison during the disease course, both in terms of speech, writing and auditory perception ${ }^{(6)}$.

Few studies have reported normal P300 values for different age ranges compared to other diagnostic procedures, mainly regarding the parameters used for assessment and electrode positioning. A normative $\mathrm{P} 300$ study $^{(7)}$ to establish latency and amplitude values for healthy young adults has reported wide variation.

There is no scientific evidence on the variability of latency measurements and P300 amplitude depending on the task given to the patient, and the best position of the active electrode.

Thus, the present study aimed to analyze latency and amplitude responses of P300 CP in normal individuals of both genders, in different positions for $\mathrm{Fz}$ and $\mathrm{Cz}$ electrodes and in different tasks of infrequent stimulus identification.

\section{METHODS}

Cross-sectional comparative study with 40 healthy volunteers (20 males and 20 females) aged 18 to 30 years (mean age: 22 years old) with normal hearing and with no signs of neuropsychological problems. The study was approved by the
Institutional Research Ethics Committee (number 12790/2011) and all individuals signed an informed consent.

Some variables were controled (e.g. drug use, physical activity, and women hormonal cycle) in view of their influences on measurements of P300 latency and amplitude. The sensitive auditory was determined with pure-tone threshold audiometry ( 250 to $8000 \mathrm{~Hz}$ ), speech audiometry thresholds, tympanometry and determination of ipsilateral and contralateral acoustic reflex at frequencies of 500, 1000, 2000 and $4000 \mathrm{~Hz}$. Individuals with thresholds of more than $20 \mathrm{dBHL}$, type A tympanometry curve and presence of acoustic reflexes of stapedius muscle in the condition of contralateral afferent pathway were considered to have normal hearing.

The $\mathrm{P} 300$ test was performed using a Bio-Logic ${ }^{\circledR}$ apparatus, version 5.70 - model 317 , tone burst stimulus, a $50.000 \mu \mathrm{V}$ gain, $75 \mathrm{dBnHL}$ for infrequent $(2000 \mathrm{~Hz})$ and frequent stimuli $(1000 \mathrm{~Hz})$, presented in a binaural manner, a $1-30 \mathrm{~Hz}$ filter, a $512 \mathrm{~ms}$ window, and insertion phones as transducer. Impedance of electrodes was maintained at $3 \mathrm{k} \Omega$ or less. A total of 300 artifact-free stimuli were used $(80 \%$ frequent stimuli and $20 \%$ infrequent stimuli). The presentation rate was 1.1 stimuli per second.

Electrodes were positioned as proposed by Jasper ${ }^{(8)}$, i.e., the active electrodes were positioned at $\mathrm{Cz}$ and $\mathrm{Fz}$ and were connected to entry 1 of the preamplifier of channels 1 and 2, respectively. Reference electrodes were placed on the earlobe (A1 and A2), interlinked and connected to entry 2 of channel 1 and interlinked to channel 2 by the jumper of the preamplifier. The ground electrode was placed at Fpz.

The subject was asked to identify the infrequent stimulus in three different tasks, i.e., 1) mental count (MC); 2) raising the right index finger (RI), and 3) pronouncing the word "thin" (PT), as illustrated in Figure 1. The order of the tasks was randomized.

The individuals were instructed to keep their eyes closed during the test in order to avoid the interference of the electrical activity of random or rapid eye movements such as blinking during the P300 recording.

The identification of infrequent stimuli, independently of the task, was controlled by the examiner, with replies containing the correct number of infrequent stimuli presented or with variations of more or less three numbers being accepted.

Data were tabulated and statistically analyzed with the $\mathrm{SAS}^{\circledR}$ 9.0 software using linear mixed-effects regression models (random and fixed effects), with the level of significance set at $p \leq 0.05$.

\section{RESULTS}

The descriptive analysis results (mean, standard and median deviation) of the P300 latency and amplitude measurements at the different position of electrode placement $(\mathrm{Cz}$ and $\mathrm{Fz})$ in the three different tasks of infrequent stimulus identification (MC, $\mathrm{RI}$ and PT) and in the comparison of males and females in the same situation of $\mathrm{P} 300$ variability are presented in Tables 1 and 2 .

Throughout the study, the latency and amplitude values of P300 (mean \pm SD) for the overall sample were $296.14 \pm 15.95 \mathrm{~ms}$ and $5.72 \pm 0.75 \mu \mathrm{V}$, respectively. At the $\mathrm{Cz}$ and Fz positions, P300 latency and amplitude values were $282.70 \pm 5.06 \mathrm{~ms}$ 


\section{B I O - L O G I C B VOK B D P O T B N T I A L R B P O R T}

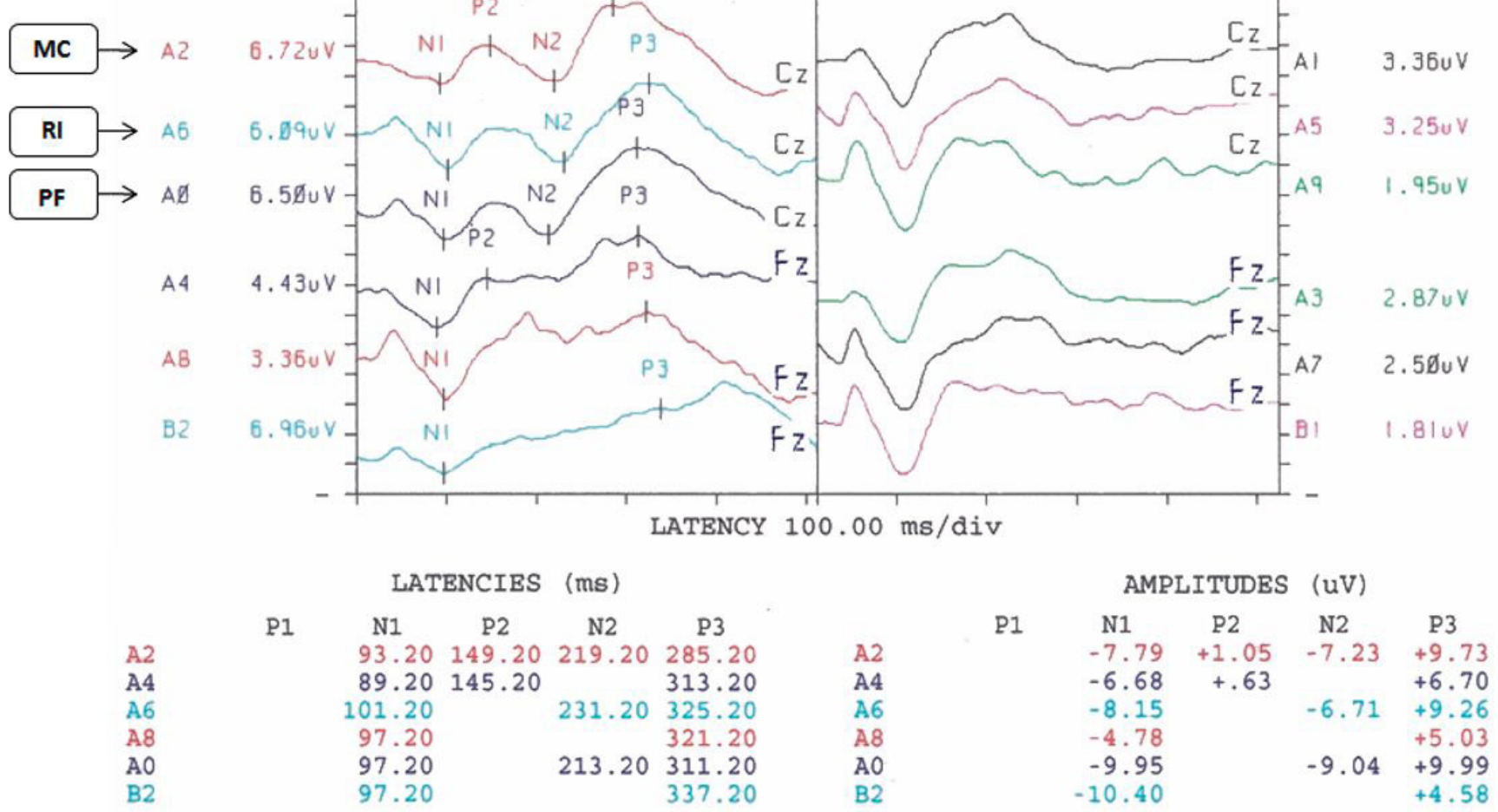

Caption: $\mathrm{Cz}=$ central position of the electrode at the central lobule; Fz = central position of the electrode at the frontal lobule; $\mathrm{SD}=\mathrm{standard}$ deviation; $\mathrm{MC}=$ menta count; $\mathrm{RI}=$ raising the right index finger; $\mathrm{PT}=$ pronouncing the word "thin"; $\mathrm{ms}=$ milliseconds; $\mu \mathrm{V}=$ microvolts

Figure 1. Example of P300 test performed in the present study, with markings in the three tasks of infrequent stimulus identification

Table 1. P300 mean, standard deviation and median latency and amplitude for males and females in the positions of electrode placement at $\mathrm{Cz}$ and $\mathrm{Fz}(\mathrm{N}=40)$

\begin{tabular}{|c|c|c|c|c|c|}
\hline & & \multicolumn{4}{|c|}{ P300 } \\
\hline & & \multicolumn{2}{|c|}{ LATENCY (ms) } & \multicolumn{2}{|c|}{ AMPLITUDE $(\mu \mathrm{V})$} \\
\hline & & $\mathrm{Cz}$ & $\mathbf{F z}$ & $\mathrm{Cz}$ & Fz \\
\hline \multirow{3}{*}{$\begin{array}{l}\text { MALE } \\
(\mathrm{N}=20)\end{array}$} & Mean & 286.29 & 306.86 & 5.85 & 4.91 \\
\hline & SD & 39.61 & 41.26 & 2.9 & 2.94 \\
\hline & Median & 284.2 & 316.2 & 5.53 & 4.2 \\
\hline \multirow{3}{*}{$\begin{array}{c}\text { FEMALE } \\
(\mathrm{N}=20)\end{array}$} & Mean & 279.12 & 312.31 & 6.69 & 5.46 \\
\hline & SD & 37.46 & 42.18 & 2.98 & 2.76 \\
\hline & Median & 269.2 & 317.2 & 6.67 & 5.14 \\
\hline
\end{tabular}

Caption: $\mathrm{Cz}=$ central position of the electrode at the central lobule; Fz = central position of the electrode at the $\mathrm{c}$ frontal lobule; SD = standard deviation; $\mathrm{ms}=$ milliseconds; $\mu \mathrm{V}=$ microvolts

and $309.58 \pm 3.85 \mathrm{~ms}$ for latency and $6.27 \pm 0.59 \mu \mathrm{V}$ and $5.18 \pm 038 \mu \mathrm{V}$ for amplitude, respectively.

When the results of latency and amplitude measurements were compared according to electrode positioning at $\mathrm{Cz}$ and $\mathrm{Fz}$, we detected a significant difference for latency $(\mathrm{p}=0.0001)$ and amplitude $(<.0001)$, with the electrode position on $\mathrm{Cz}$ showing the lowest latencies and highest amplitudes.

Comparison of male and female genders did not show a difference for latency $(\mathrm{p}=0.9313)$ or amplitude $(\mathrm{p}=0.1960)$ in the studied sample.
Analysis of latency measurements according to the three different tasks requested for identification of the infrequent stimulus showed a difference only between PT and RI tasks $(p=0.0320)$, with a lower latency for RI task, as shown in Table 3 . When comparing the position of electrode placement according to the three different tasks for identification of the infrequent stimulus, we observed a difference for $\mathrm{MC}(\mathrm{p}=0.0035)$, RI $(p=0.0008)$ and PT $(p<0.0001)$, with a lower latency with the electrode in the $\mathrm{Cz}$ position, as seen in Table 4.

There was no difference in P300 latency for females in different tasks for identification of infrequent stimulus, whereas 
Table 2. P300 mean, standard deviation and median latency and amplitude for males and females in the positions of electrode placement at $\mathrm{Cz}$ and $\mathrm{Fz}$, according to the different tasks $(\mathrm{N}=40)$

\begin{tabular}{|c|c|c|c|c|c|c|}
\hline & & & \multicolumn{4}{|c|}{ P300 } \\
\hline & & & \multicolumn{2}{|c|}{ LATENCY (ms) } & \multicolumn{2}{|c|}{ AMPLITUDE $(\mu \mathrm{V})$} \\
\hline & & & $\mathrm{Cz}$ & Fz & $\mathbf{C z}$ & $\mathrm{Fz}$ \\
\hline \multirow{6}{*}{ MC } & \multirow{3}{*}{ MALE } & Mean & 282.88 & 298.25 & 5.79 & 3.81 \\
\hline & & SD & 35.99 & 41.07 & 2.88 & 2.26 \\
\hline & & Median & 277.2 & 298.2 & 5.15 & 3.76 \\
\hline & \multirow{3}{*}{ FEMALE } & Mean & 286.85 & 310.26 & 6.76 & 4.73 \\
\hline & & SD & 38.68 & 46.66 & 2.82 & 1.43 \\
\hline & & Median & 274.2 & 320.2 & 7.14 & 4.88 \\
\hline \multirow{6}{*}{$\mathbf{R I}$} & \multirow{3}{*}{ MALE } & Mean & 292.41 & 322.26 & 5.79 & 6.02 \\
\hline & & SD & 43.64 & 45.16 & 2.88 & 3.77 \\
\hline & & Median & 299.2 & 335.2 & 5.73 & 4.89 \\
\hline & \multirow{3}{*}{ FEMALE } & Mean & 274.65 & 323.48 & 6.99 & 7.14 \\
\hline & & SD & 38.43 & 42.07 & 3.41 & 3.75 \\
\hline & & Median & 262.2 & 334.2 & 6.26 & 5.75 \\
\hline \multirow{6}{*}{ PT } & \multirow{3}{*}{ MALE } & Mean & 283.42 & 302.95 & 5.99 & 4.65 \\
\hline & & SD & 40.33 & 34.42 & 3.13 & 2.32 \\
\hline & & Median & 282.2 & 315.2 & 5.52 & 4.13 \\
\hline & \multirow{3}{*}{ FEMALE } & Mean & 276.73 & 304.66 & 6.33 & 4.46 \\
\hline & & SD & 36.16 & 36.74 & 2.8 & 1.92 \\
\hline & & Median & 269.2 & 309.2 & 6.39 & 4.53 \\
\hline
\end{tabular}

Caption: $\mathrm{Cz}=$ central position of the electrode at the central lobule; Fz = central position of the electrode at the frontal lobule; $\mathrm{SD}=\mathrm{standard}$ deviation; $\mathrm{MC}=$ mental count; $\mathrm{RI}=$ raising the right index finger; $\mathrm{PT}=$ pronouncing the word "thin"; $\mathrm{ms}=$ milliseconds; $\mu \mathrm{V}=$ microvolts

Table 3. Estimated difference and p value for P300 latency and amplitude measurements when comparing the three tasks for the identification of the infrequent stimulus (MC, $\mathrm{RI}$ and $\mathrm{PT})(\mathrm{N}=40)$

\begin{tabular}{|c|c|c|c|}
\hline & TASKS & ESTIMATE & P VALUE * \\
\hline \multirow{3}{*}{ 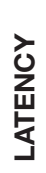 } & $M C-P T$ & -6.9665 & 0.1226 \\
\hline & $M C-R I$ & 2.8799 & 0.5236 \\
\hline & PT - RI & 9.8464 & 0.0320 \\
\hline \multirow{3}{*}{ 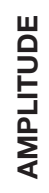 } & $\mathrm{MC}-\mathrm{PT}$ & -1.1686 & 0.0022 \\
\hline & $\mathrm{MC}-\mathrm{RI}$ & -0.00293 & 0.9938 \\
\hline & $\mathrm{RI}$ - PT & 1.1657 & 0.0025 \\
\hline
\end{tabular}

${ }^{*} \mathrm{p} \leq 0.05$, statistically significant value

Caption: $\mathrm{MC}=$ mental counting; $\mathrm{RI}=$ raising the right index finger; PT = pronouncing the word 'thin'

Table 4. Estimated difference and $p$ value for $P 300$ latency measurements when the position of electrode placement was compared to the three different tasks for the identification of the infrequent stimulus (MC, RI and $\mathrm{PT})(\mathrm{N}=40)$

\begin{tabular}{cccc}
\hline TASK & ELECTRODE & ESTIMATE & P VALUE * \\
\hline MC & $\mathrm{C} z-\mathrm{Fz}$ & -18.6099 & 0.0035 \\
PT & $\mathrm{C} z-\mathrm{Fz}$ & -37.4724 & $<.0001$ \\
RI & $\mathrm{C} z-\mathrm{Fz}$ & -22.0861 & 0.0008 \\
\hline
\end{tabular}

${ }^{*} \mathrm{p} \leq 0.05$, statistically significant value

Caption: $\mathrm{Cz}=$ central position of the electrode at the central lobule; $\mathrm{Fz}=$ central position of the electrode at the frontal lobule; $\mathrm{MC}=$ mental counting; $\mathrm{RI}=$ raising the right index finger; $\mathrm{PT}=$ pronouncing the word 'thin' a difference was detected between MC and PT $(\mathrm{p}=0.0299)$ for the males.

Analysis of the amplitude values detected in the sample for the three different tasks for identification of infrequent stimulus revealed a difference between MC and PT $(\mathrm{p}=0.0022)$ and between RI and PT ( $p=0.0025)$. The highest amplitude values were observed for RI task, followed by PT and MC.

There was no difference in mean amplitude among the three different tasks for identification of infrequent stimulus in the males, i.e., $\mathrm{MC}$ and $\mathrm{PT}(\mathrm{p}=0.0724), \mathrm{MC}$ and $\mathrm{RI}(\mathrm{p}=0.5488)$, and PT and RI $(p=0.2493)$. For females, there was a difference in mean amplitude between the three tasks, i.e., MC and PT $(p=0.0100)$ and PT and RI $(p v=0.0014)$. PT was the task for identification of infrequent stimulus that showed the greatest amplitude of P300, Table 5.

\section{DISCUSSION}

Factors that could interfere with the recording of endogenous potentials are often described in the literature, such as age, gender, help states, awareness, psychological conditions, circadian cycle, among others. The type of the task is another factor that has drawn attention from researchers about changes in amplitude measures and P300 latency recordings.

The average of latency measurements and amplitude of P300 for three infrequent stimulus identification tasks were $296.14 \mathrm{~ms}$ and $5.69 \mu \mathrm{V}$; values within the range given in the 
Table 5. Estimated difference and $\mathrm{p}$ value for P300 latency and amplitude measurements when males and females were compared to the three different tasks for the identification of the infrequent stimulus (MC, $\mathrm{RI}$ and PT) $(\mathrm{N}=40)$

\begin{tabular}{|c|c|c|c|c|}
\hline & SEXES & TASKS & ESTIMATE & P VALUE * \\
\hline \multirow{6}{*}{ 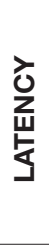 } & \multirow{3}{*}{$\mathbf{F}$} & $\mathrm{MC}-\mathrm{PT}$ & 0.09614 & 0.9878 \\
\hline & & $\mathrm{MC}-\mathrm{RI}$ & 6.9206 & 0.2675 \\
\hline & & PT - RI & 6.8245 & 0.2755 \\
\hline & \multirow{3}{*}{ M } & $\mathrm{MC}-\mathrm{PT}$ & -14.0291 & 0.0299 \\
\hline & & $\mathrm{MC}-\mathrm{RI}$ & -1.1609 & 0.8589 \\
\hline & & PT - RI & 12.8683 & 0.0542 \\
\hline \multirow{6}{*}{ 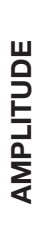 } & \multirow{3}{*}{$\mathbf{F}$} & $\mathrm{MC}-\mathrm{PT}$ & -1.3695 & 0.0100 \\
\hline & & $\mathrm{MC}-\mathrm{RI}$ & 0.3213 & 0.5379 \\
\hline & & PT - RI & 1.6908 & 0.0014 \\
\hline & \multirow{3}{*}{ M } & $\mathrm{MC}-\mathrm{PT}$ & -0.9677 & 0.0724 \\
\hline & & $\mathrm{MC}-\mathrm{RI}$ & -0.3272 & 0.5488 \\
\hline & & PT - RI & 0.6405 & 0.2493 \\
\hline
\end{tabular}

${ }^{*} \mathrm{p} \leq 0.05$, statistically significant value

Caption: $\mathrm{F}$ = female sex; $\mathrm{M}=$ male sex; $\mathrm{MC}=$ mental counting; $\mathrm{RI}=$ raising the right index finger; $\mathrm{PT}=$ pronouncing the word 'thin'

literature for the reference values established for young adults and adults, 17-30 years ${ }^{(9,10)}$.

In this study, there was no significant difference when comparing genders with average latency and amplitude of P300 recordings. There is no consensus in the literature regarding the difference of latency and amplitude measures between genders. Investigations, with similar results to those found in this study ${ }^{(11,12)}$, also confirmed that there was no relationship between the variable gender with variations in latency and amplitude. However, Franco ${ }^{(2)}$ shows the difference between genders, with lowest average values and standard deviation for P300 latency for females. Possibly the issue of latency measures variability related to gender, regarding the hormonal cycle influence, will remain as objective of difficult monitoring.

When comparing the $\mathrm{P} 300$ results obtained when placing the electrodes at $\mathrm{Cz}$ and $\mathrm{Fz}$, there is a difference between latency measurements $(\mathrm{p}<0.0001)$ and amplitude $(\mathrm{p}=0.0001)$, with better wave morphology when the electrode was positioned at $\mathrm{Cz}$ (Table 4).

It is recommended the placement as close as possible to the surface electrode presumed as neural generator ${ }^{(1)}$. Recommendations observed in different studies are the placement of active electrodes at $\mathrm{Cz}$ and $\mathrm{Fz}$ or $\mathrm{Cz}, \mathrm{Fz}$ and $\mathrm{Pz}$ or just $\mathrm{Fz}$ or $\mathrm{Cz}^{(12-15)}$. The variation in the positioning of anterior frontal portion and the posterior occipital portion decreases the amplitude of the waves, showing that the maximum amplitude is generally obtained at $\mathrm{Fz} / \mathrm{Cz}$ or the electrode position $\mathrm{Fz} / \mathrm{Pz}^{(4)}$.

The values of latency and amplitude, with the fixed electrodes at $\mathrm{Cz}$ and $\mathrm{Fz}$, found in this research (Table 1), equated to values obtained by Franco ${ }^{(2)}$. The difference between the electrodes positions of Fz-Pz and Cz-Pz (Table 3), for latency, was also described by Duarte et al. ${ }^{(12)}$.

Thus, these results reinforce the best placement of the electrode for capturing the potential cognitive P300 in Cz position.

The type of task requested for P300 evaluation is another factor to be considered when performing the exam, since attention is a condition required for the characteristic wave of the cognitive potential to be observed ${ }^{(16)}$. Many of the published papers failed to describe the specific information on the type of task requested for the participants to identify the infrequent stimulus. They reported the type of command, such as "pay attention to the infrequent stimulus," and "respond only to the infrequent stimulus"(17-19). The types of tasks requested for the identification of the stimulus infrequent detected in the literature surveyed were: "mental counting"(2,3,7,9,11,20,21); "raising the finger"(6); "counting aloud"(12,22); "pressing the button"(23,24) and "counting and raising one hand"(25).

Although the task of "mentally counting" has been the most found in the literature, it is also the task that can cause more difficulties for the record analysis, because the patients with cognitive disorders or without evaluator effect control to the number reported at the end of the test can compromise the performance of the task or registration. Therefore, the performance relative to the task should be analyzed by the evaluator, in order to ensure that the measures of amplitude and latencies obtained during the registration reflect the proposition of the test. It seeks to understand the test answers variation based on the task to control the variable type of task in the clinical use of the P300, when it is used to help the assessment of the individual's ability of processing auditory information.

In the present study, the subjects performed three tasks in order to identify the infrequent stimulus (MC, PT and RI). Comparing the latency measurements regarding gender and type of task requested to the participant; we observed significant difference for males when MC and PT tasks were compared $(\mathrm{p}=0.0299)$ (Table 5).

Regarding the comparison of the measures range with the types of task required to the participant to observe significant difference for PT task (MC - PT p $=0.0022$ and RI - PT p = 0.0025), observed on the Table 3 . When comparing gender and task type, only females showed a significant difference when comparing MC and PT tasks $(\mathrm{p}=0.0100)$ and RI and PT $(\mathrm{p}=0.0014)$, on the Table 5. The comparison between the tasks counting infrequent stimuli and raising one hand when hearing them has already been studied for the measurements of latency and amplitude, with no difference observed between them ${ }^{(25)}$. A similar finding was reported when comparing the same measurements to two types of passive tasks, i.e., the task sequencing and an the original task ${ }^{(26)}$.

However, reports that task type can influence results of long-latency auditory evoked potentials are present in the literature $^{(27)}$. The authors concluded that the complex N1, P2, N2 has not changed, but P300 has showed slight change showing up earlier in the procedure with lower cognitive complexity.

The motor act of raising a hand to identify the perception of the infrequent stimulus has been reported as easiest and it is believed that this task can be adapted for individuals with difficulties in the exam just mentally counting ${ }^{(25)}$.

Another factor to consider is the necessity to choose one task type to control the maintenance of the evaluated answer more efficiently. During the recordings, in certain populations, the absence of P3 wave may be due to no control of individual attention (e.g. when you are mentally counting) which can be 
easily checked by the researcher to ask the task of "raising the index finger" when the individual hears the infrequent stimulus, linking the motor act to the appearance of infrequent stimulus.

The task with a verbal response is more complex, indicating a need for learning or neuromaturation of the nervous system ${ }^{(28)}$. Still according to the author ${ }^{(22)}$, naming, a linguistic activity, demands dependent processes of complex connections of thinking with the language ${ }^{(28)}$. The mean values of P300 latencies are higher for verbal than non-verbal stimuli and, conversely, the mean amplitudes are lower for verbal than non-vebal stimuli ${ }^{(22)}$.

For the three studied tasks, the mean lowest latency result was found for task MC (282.88 ms). Significance was observed only when task PT was compared to RI $(\mathrm{p}=0.032)$, showing the highest values of latency for the latter (Table 3). These results raise important questions regarding the choice of task to be requested for the participant, since it is a significant factor both for controling the correct performance of the test, i.e., ensuring that the participant is attentive and that the response (recorded or not), actually depicts the condition of the subject, and the interpretation of the examiner according to the chosen task.

The temporal sequencing task, such as MC, involves both brain hemispheres, with different functions but working together regardless of the stimulated ear ${ }^{(28)}$. The right hemisphere may be responsible for the recognition of the acoustic contour and the left one for temporal sequencing and for naming what was heard ${ }^{(29)}$. Thus, the difficulty in the naming modality may be explained by the need for interhemispheric integration of the stimuli via the corpus callosum in the request of a verbal response, a fact that did not occur with a non-verbal request ${ }^{(30)}$.

\section{CONCLUSION}

The mean latency and amplitude values detected were $296.14 \pm 15.95 \mathrm{~ms}$ and $5.72 \pm 0.75 \mu \mathrm{V}$, respectively. The best values of latency and amplitude were obtained when at $\mathrm{Cz}$ position, with higest amplitude and latency nearest to $300 \mathrm{~ms}$. However, when associated with gender, there was no variations in these measures between the electrode positions ( $\mathrm{Fz}$ and $\mathrm{Cz}$ ). Lowest latencies were obtained for the PT task and the highest amplitudes for the RI task.

\section{REFERENCES}

1. Musiek FE. Probing brain function with acoustic stimuli. ASHA. 1989;31(8):100-6, 55. PMid:2679565.

2. Franco GM. O potencial evocado cognitivo em adultos normais. Arq Neuropsiquiatr. 2001;59(2-A):198-200. http://dx.doi.org/10.1590/S0004282X2001000200008. PMid:11400024.

3. Hall J. New handbook of auditory evoked responses. Boston: Allayn \& Bacon; 2006.

4. Schochat E, Scheuer CI, Andrade ER. ABR and auditory P300 findings in children with ADHD. Arq Neuropsiquiatr. 2002;60(3-B):742-7. http:// dx.doi.org/10.1590/S0004-282X2002000500012. PMid:12364942.

5. Kececi H, Degirmenci Y, Atakay S. Habituation and dishabituation of P300. Cogn Behav Neurol. 2006;19(3):130-4. http://dx.doi.org/10.1097/01. wnn.0000213911.80019.c1. PMid:16957490.

6. Reis ACMB, Frizzo ACF, Isaac ML, Garcia CFD, Funayama CAR, Iório MCM. P300 in individuals with sensorineural hearing loss. Braz
J Otorhinolaryngol. 2015;81(2):126-32. http://dx.doi.org/10.1016/j. bjorl.2014.10.001. PMid:25458253.

7. Colafêmina JF, Fellipe ACN, Junqueira CAO, Frizzo AC. Potenciais evocados auditivos de longa latência (P300) em adultos jovens saudáveis: um estudo normativo. Braz J Otorhinolaryngol. 2000;66:144-8.

8. Jasper HH. The ten-twenty electrode system of the international federation. Electroencephalogr Clin Neurophysiol Suppl. 1958;10:371-5.

9. McPherson DL. Late potential of the auditory system. San Diego: Singular Publishing Group; 1996. p. 147.

10. Kraus N, McGee T. Auditory event-related potentials. In: Katz J, editor. Handbook of clinical auditory. 4th ed. Baltimore: Williams \& Wilkins; 1994. p. 406-26.

11. Costa SMB, Costa AO Fo, Cardoso MRA. Os efeitos da idade e sexo na latência do P300. Braz J Otorhinolaryngol. 2002;68:891-4.

12. Duarte JL, Alvarenga KF, Banhara MR, Melo ADP, Sás RM, Costa AO Fo. Potencial evocado auditivo de longa latência-P300 em indivíduos normais: valor do registro simultâneo em Fz e Cz. Braz J Otorhinolaryngol. 2009;75(2):231-6. http://dx.doi.org/10.1016/S1808-8694(15)30783-7. PMid:19575109.

13. Courchesne E. Changes in P3 waves with event repetition: Long-term effects on scalp distribution and amplitude. Electroencephalogr Clin Neurophysiol. 1978;45(6):754-66. PMid:84743.

14. Oken BS. Endogenous event-related potentials. In: Chiappa KH, editor Evoked potentials in clinical medicine. Philadelphia: Lippincott-Raven; 1997. p. 529-64.

15. Hall JWIII, Mueller HGIII. Audiologists' desk reference. San Diego: Singular Publishing Group; 1997. p. 389-428.

16. Polich J. Theoretical overview of P3a and P3b. In: Polich J, editor. Detection of change: event-related potential and fMRI findings. Boston: Kluwer Academic Press; 2003. p. 83-98.

17. Pineroli JCA, Campos DS, Wiemes GR, Meneses MS, Mocellin M. Avaliação auditiva central com BERA e P300 na Doença de Parkinson. Braz J Otorhinolaryngol. 2002;68:462-6.

18. Wiemes GR, Kozlowski L, Mocellin M, Hamerschmidt R, Schuch LH Potencial evocado cognitivo e desordem de processamento auditivo em crianças com distúrbios de leitura e escrita. Braz J Otorhinolaryngol. 2012;78(3):91-7. http://dx.doi.org/10.1590/S1808-86942012000300016. PMid:22714853.

19. Miranda EC, Pinheiro MMC, Pereira RI, Iorio MMC. Correlação do potencial evocado P300 com aspectos cognitivos e depressivos do envelhecimento. Braz J Otorhinolaryngol. 2012;78(5):83-9. PMid:23108825.

20. Magliaro FCL, Matas SLA, Matas CG. Potencial Cognitivo P300 em pacientes com lesão isquêmica do hemisfério direito. Pró-Fono Rev At Ci. 2009;21:285-90.

21. Jiménez-Arriero MA, Rodríguez-Torresano J, Ponce G, Hoenicka J, Rodríguez R, Rubio G, et al. P300 in alcohol dependence: effects of TaqI-A genotype. Eur J Psychiatry. 2009;23(4):225-33. http://dx.doi.org/10.4321/ S0213-61632009000400003.

22. Massa CGP, Rabelo MC, Matas CG, Schochat E, Samelli AG. P300 com estímulo verbal e não verbal em adultos normo-ouvintes. Braz J Otorhinolaryngol. 2011;77(6):686-90. PMid:22183272.

23. Neshige R, Barrett G, Shibasaki H. Auditory long latency event-related potentials in Alzheimer's disease and multi-infarct dementia. J Neurol Neurosurg Psychiatry. 1988;51(9):1120-5. http://dx.doi.org/10.1136/ jnnp.51.9.1120. PMid:3225596.

24. Katayama J, Polich J. P300 from one-, two-, and three-stimulus auditory paradigms. Int J Psychophysiol. 1996;23(1-2):33-40. http://dx.doi. org/10.1016/0167-8760(96)00030-X. PMid:8880364.

25. Machado CSS, Carvalho ACO, Silva PLG. Caracterização da normalidade do P300 em adultos jovens. Rev Soc Bras Fonoaudiol. 2009;14(1):83-90. http://dx.doi.org/10.1590/S1516-80342009000100014.

26. Iwanami A, Kamijima K, Yoshizawa J. P300 component of event-related potentials in passive tasks. Int J Neurosci. 1996;84(1-4):121-6. http:// dx.doi.org/10.3109/00207459608987257. PMid:8707473. 
27. César CPHAR, Munhoz MSL. O P300 auditivo em jovens e adultos saudáveis como uma nova proposta de resposta: levantar a mão. Acta AWHO. 1999;18:32-7.

28. Frederigue-Lopes NB, Bevilacqua MC, Sameshima K, Costa OA. Desempenho de crianças normais em testes temporais auditivos em campo livre. Pró-Fono Rev At Ci. 2010;22:83-8.

29. Mustek FE, Pinheiro ML. Frequency patterns in cochlear, brainstem, and cerebral lesions. Audiology. 1987;26(2):79-88. http://dx.doi. org/10.3109/00206098709078409. PMid:3606474.

30. Musiek FE. The frequency pattern test: a guide. Hear J. 2002;55(6):58. http://dx.doi.org/10.1097/01.HJ.0000293280.99394.dd.

\section{Author contributions}

HOS contribution with conception and design of the study, preparation of schedule, literature review, data collection, analysis and interpretation of data, article writing; ACFF contribution with analysis and interpretation of data, article writing and approval of the final version; SZ contributions with analysis and interpretation of data, article writing and critical review of the final version; $M A H$ contribution with: analysis and interpretation of data, article writing and critical review of the final version; $A C M B R$ contributions like advisor professor, principal investigator, conception and design of the study, preparation of schedule, literature survey, collection, analysis and interpretation of data, article writing and approval of the final version. 